\title{
CAMBIOS OCUPACIONALES EN LOS CONTEXTOS RURALES DE MÉXICO*
}

\author{
FELIPE CONTRERAS MOLOTLA* \\ EL COLEGIO DE MÉXICO
}

Recibido/ Received/ Recebido: 30/08/2012 - Aceptado/ Accepted/Aprovado: 01/04/2013

\begin{abstract}
Resumen
El objetivo de este trabajo es realizar una revisión de los principales cambios en la estructura ocupacional y las condiciones laborales de la fuerza de trabajo en las áreas rurales de México. A partir de la información de la Muestra del Censo General de Población y Vivienda del año 2000 y 2010 se analiza la información de 27 grupos de ocupación y nueve regiones geollustracions, a la luz del proceso de consolidación de las reformas económicas en el contexto rural mexicano en las últimas décadas. Entre los resultados de mayor interés se confirma la disminución de la población ocupada en actividades agropecuarias, la creciente inserción laboral de las mujeres en ocupaciones no agropecuarias, la mayor presencia de varones en ocupaciones agropecuarias no tradicionales, las diferencias de oportunidades laborales entre las regiones Norte y Sur de México, y la contracción de la oferta de empleos tanto agropecuarios como no agropecuarios.
\end{abstract}

Palabras clave: Ocupaciones, Mercados de trabajo, Rural, México.

\section{OCCUPATIONAL CHANGES IN MEXICO RURAL CONTEXT}

\begin{abstract}
This article reviews main changes in occupational structure and labor conditions of workforce in Mexican rural areas. Using information from the Sample of the General Census of Population and Dwelling 2000 and 2010 the information of 27 occupation groups and 9 geographic regions is analyzed, considering the consolidation process from economic reforms in Mexican rural context in the last two decades. Among interest results, is the confirmation of decrease of occupied population in agricultural activities, women employment increase in non-agricultural occupations, greater men presence in notraditional agricultural occupations, differences in labor opportunietes between South and Northen Mexican regions, and reduction work supply in agricultural and non-agricultural sectors.
\end{abstract}

Keywords: Occupations, Labor martket, Rural, Mexico.

Artículo de investigación para el Grupo de Trabajo de Mercados Laborales.

* Estudiante del Doctorado en Estudios de Población, El Colegio de México. Correo electrónico: fcontreras@colmex.mx 


\title{
MUDANÇAS OCUPACIONAIS NOS CONTEXTOS RURAIS DO MÉXICO
}

\section{Resumo}

\begin{abstract}
O objetivo deste trabalho é realizar uma revisão das principais mudanças na estrutura ocupacional $e$ as condições laborais da força de trabalho nas áreas rurais do México. A partir da informação da Mostra do Censo Geral de População e Moradia do ano 2000 e 2010 se analisa a informação de 27 grupos de ocupação em nove regiões geollustracions, à luz do processo de consolidação das reformas econômicas no contexto rural mexicano nas últimas décadas. Entre os resultados de maior interesse se confirma a diminuição da população ocupada em atividades agropecuárias, a crescente inserção laboral das mulheres em ocupações não agropecuárias, a maior presença de homens em ocupações agropecuárias não tradicionais, as diferenças de oportunidades de trabalho entre as regiões Norte e Sul do México, e a contração da oferta de empregos tanto agropecuários como não agropecuários.
\end{abstract}

Palavras chave: Ocupações, Mercados de trabalho, Rural, México.

Contreras, F. (2013) Cambios ocupacionales en los contextos rurales de México. En: Revista de la Facultad de Ciencias Económicas de la Universidad Militar Nueva Granada. rev.fac. cienc.econ, XXI (1)

JEL: J43, J82, J08.

\section{Introducción}

Cuando se trata de transformaciones, económicas y sociales en las áreas rurales, es difícil pasar por alto una perspectiva que en las últimas décadas ha intentado ofrecer un marco explicativo sobre los cambios que han ocurrido recientemente en el campo. La 'nueva ruralidad' es una visión que resulta ser polémica entre los especialistas.

Esta visión tiene su origen en Europa a principios de los años ochenta bajo el contexto de la transformación del campo vinculado con el desarrollo tecnológico. En ese sentido, se modificó la perspectiva de análisis de los estudios agrarios centrados en el problema de la tierra, a los estudios rurales que abarca el conjunto de problemas más amplios, que tenían que ver con la vinculación entre las áreas rurales con las urbanas y, que involucraba una dinámica económica con un conjunto de actividades diversificadas (García Bartolomé, 1996, referido por Grammont, 2010).

En América Latina la idea de la nueva ruralidad surge, a partir del fortalecimiento de la producción agroindustrial y el debilitamiento de la agricultura de subsistencia o para el autoconsumo que comenzó a ser complementaria del ingreso en los hogares rurales. A mediados de los años noventa comienzan a plantearse una perspectiva denominada 'nueva ruralidad', la cual intenta ser un enfoque a través del cual se pueden explicar las transformaciones en las zonas agrícolas, a partir de los cambios estructurales y la globalización económica (Grammont, 2010, Grammont, 2004; Llambí \& Pérez, 2006; Larralde, 2008).

Los principales cambios que se contemplan se refieren a lo denominado "rural", lo que tradicionalmente se concibió como una forma de organización alrededor de las actividades de producción agrícolas, en contraste con lo denominado urbano, en el que los procesos productivos se dan a través de la industria, el comercio y los servicios principalmente.

Grammont (2010), señala que el concepto de 'nueva ruralidad' es impreciso y polisémico pero que ayuda a comprender y entender los fenómenos que ocurren en las áreas rurales en convivencia con las zonas urbanas y reconoce que su ambigüedad se debe al uso empírico que se le da y no a la reflexión conceptual en la construcción de un marco teórico. Y señala que se pueden distinguir cuatro líneas que se contraponen al concepto: i) la teoría de los 
nuevos actores o nuevos movimientos sociales; ii) la sociología de la agricultura y no la sociología de lo rural, en la que consideran que no hay cabida en el espacio social, lo rural, en lugar del espacio sectorial; iii) una tercera línea es una posición en la que existe una postura en la que se concibe a la 'nueva ruralidad' como una nueva mirada de los estudiosos y no a una nueva realidad; $y$ iv) finalmente, se encuentra una posición muy generalizada que ve en el concepto como un potencial explicativo a pesar de que reconoce sus limitaciones, debido a que se ha utilizado más el enfoque de una manera descriptiva más que analítica.

Por otro lado, hay posiciones que matizan el empleo del concepto, entre ellos se encuentran autores como Appendini \& Torres-Mazuera (2008), que han manifestado que la definición de 'nueva ruralidad' lleva consigo una connotación positiva y que remite a una imagen de la ruralidad más desarrollada, moderna e incluso económicamente exitosa, que dista mucho de la realidad que han observado en el centro de México.

Podemos afirmar que el enfoque de la 'nueva ruralidad' es una óptica a través de la cual se pueden observar e interpretar las articulaciones entre los mercados de trabajo regionales; entre el campo y la ciudad, las multiactividades, la mayor presencia de actividades económicas del sector secundario y terciario en los espacios rurales.

Bajo esta reflexión polémica existe un tema en el que coinciden los distintos autores. En que la realidad que se observa en el campo es distinta a la que se podía distinguir hasta hace algunas décadas, debido a que ha disminuido la centralidad de las actividades agrícolas en los hogares rurales, dando paso a la centralidad de los ingresos que provienen de actividades vinculadas con ocupaciones no agropecuarias. De esta forma, una preocupación de este trabajo es explorar de manera detallada los cambios entre las ocupaciones que se presentan en la primera década de este siglo en México.

Las preguntas que guían esta investigación son ¿Cómo han cambiado las estructuras ocupacionales en México entre 2000 y 2010? y ¿Cómo se manifiestan a nivel de las regiones? A lo largo de este trabajo se espera comprobar que el proceso de reestructuración económica y la escaza oferta de empleo en los mercados de trabajo local y regional han desincentivado el aumento de las ocupaciones agropecuarias y ha fomentado el crecimiento de las ocupaciones no agropecuarias con condiciones laborales precarias en las áreas rurales del México.

Por ello se presenta una revisión de los principales cambios en la estructura ocupacional y las condiciones laborales de la fuerza de trabajo en las áreas rurales $^{1}$ de México. La información se revisa a partir de 27 grupos de ocupación y, nueve regiones geográficas ${ }^{2}$. La fuente de información que se utiliza es la Muestra del Censo General de Población y Vivienda del año 2000 y 2010. Los resultados se examinan a la luz del proceso de consolidación de las reformas económicas en el campo mexicano en las últimas décadas.

Entre los resultados de mayor interés se confirma la disminución de la población ocupada en actividades agropecuarias; una tendencia en la inserción laboral de las mujeres en ocupaciones no agropecuarias; la mayor presencia de varones en ocupaciones agropecuarias no tradicionales ${ }^{3}$; diferencias de oportunidades laborales entre las regiones Norte y Sur de

1 Cuando nos referimos a localidades rurales, aludimos a las que cuentan con menos de 2 mil 500 habitantes. Existe un debate amplio sobre la definición de lo rural y de su estudio como se puede apreciar en los trabajos de Pedrero \& Embriz (1992) y Trejo (2003), entre otros.

2 Las nueve regiones que se utilizan se retoman de la propuesta que elabora el Consejo Nacional de Población (CONAPO, 2004). Presentar las regiones y cómo se encuentran integradas: Noroeste (Baja California, Baja California Sur, Sinaloa y Sonora); Norte (Coahuila, Chihuahua y Durango); Noreste (Nuevo León y Tamaulipas); Occidente (Colima, Jalisco, Michoacán y Nayarit); Centro Norte (Aguascalientes, Guanajuato, Querétaro, San Luis Potosí y Zacatecas); Centro (Distrito Federal, Hidalgo, México, Morelos, Puebla y Tlaxcala); Sur (Chiapas, Guerrero y Oaxaca); Golfo (Tabasco y Veracruz); Península (Campeche, Quintana Roo y Yucatán).

3 Por ocupaciones no tradicionales para los varones se consideraran aquellas en las que no habían tenido una presencia importante como ocurría en el caso de las mujeres en el cultivo de flores y hortalizas. 
México; contracción de la oferta de empleos tanto agropecuarios como no agropecuarios.

\section{Las principales transformaciones económicas en el campo mexicano}

El antecedente inmediato que ha afectado las condiciones económicas en el campo mexicano, sin lugar a dudas, se remiten a fechas que se encuentran alrededor de la firma del Tratado de Libre Comercio con Estados Unidos y Canadá (TLCAN), que entró en vigor en 1994. Se puede decir, que la firma de este tratado comercial contribuyo, junto con la política agropecuaria mexicana a que se debilitaran las condiciones económicas de los pequeños productores.

A principios de la década de los años noventa se definió, en parte, una serie de factores que construirían el escenario sobre el futuro de los campesinos mexicanos, en el que se vislumbraba que este conjunto pasarían de ser productores a trabajadores que dependerían en mayor medida de los ingresos que obtuvieran por salarios. A esta transición contribuyeron de forma decisiva una serie de elementos que se vinculan con: el proceso de reestructuración económica; la liberalización comercial de productos agropecuarios, lo que desincentivo la producción nacional frente a las importaciones extranjeras; las modificaciones al artículo 27, con lo cual se permite el cambio de régimen de la tenencia de la tierra; y el impulso de las políticas para promover la modernización de los procesos productivos, que evidentemente estaban destinados a los productores más dinámicos. Con lo que los productores nacionales no pudieron competir con los productos extranjeros y tuvieron que destinar sus tierras de temporal al cultivo de frijol y maíz (Appendini, 1992).

Ese era el marco que precedía a la firma del TLCAN $y$, una vez que entró en vigor, el panorama para los pequeños productores no fue muy alentador, debido a que las políticas estatales desincentivaron la rentabilidad de los cultivos de productos básicos, que no podían competir contra los grandes productores nacionales e internacionales. Un ejemplo de esta situación fue la liberalización del mercado de productos como el arroz, el sorgo y la soya (Rubio, 2001). Además no existía una estrategia que contemplara de manera central la reconversión productiva de los campesinos para que lograran incentivar su productividad y con ello que se volvieran más competitivos en el mercado.

Este conjunto de reformas económicas sentaron las bases para que los pequeños productores perdieran gradualmente su participación en el mercado y, en consecuencia, destinaran su producción en mayor medida al autoconsumo. Lo que alentó a que los miembros de los hogares rurales incursionaran en ocupaciones distintas a las vinculadas con actividades agrícolas para complementar sus ingresos, en un inicio y, que a la postre se convertirían en una de las principales fuentes de ingreso de estos hogares.

En contraparte, los productores que resultaron ser los beneficiados de este conjunto de reformas, fueron los grandes productores que destinaban su producción principalmente a la exportación, como en el caso del cultivo de las hortalizas y frutas que había ganado una mayor presencia a partir de la década de los años noventa (Rubio, 2004).

De esta forma, se enfatizan las diferencias entre los pequeños y grandes productores. Los primeros, se convirtieron en una mano de obra abundante y barata que se empleaba en los grandes campos agrícolas como jornaleros temporales o permanentes. A pesar de que este fenómeno tiene sus antecedentes en la década de los años sesenta. En tanto que los segundos, se fortalecieron y lograron tener una mayor participación, tanto en el mercado local como internacional.

Este conjunto de procesos dejaron a un amplio conjunto de hogares en situación de vulnerabilidad y de exclusión, en dimensiones de salud, alimentación y empleo. Este conjunto de condiciones precarias ha dejado en la pobreza a gran parte de la población rural que cada vez tiene menos alternativas de mejorar sus condiciones económicas. Por lo tanto, la producción agropecuaria en pequeña escala se volvió menos costeable y no logró revertir dicha tendencia. Esta situación afectó de manera directa la forma de organización de los pequeños productores, que en términos generales, se trataba de unidades productivas familiares y al ver limitada su producción agrícola tuvieron que diversificar sus estrategias de subsistencia. 
Esta situación impulsó la incursión de los miembros de los hogares rurales en ocupaciones no agropecuarias, que en un principio tenían la función de complementar su ingreso familiar, pero con el tiempo tendría un peso central en el ingreso del hogar. Por lo tanto, la población en ocupaciones agropecuarias transitaría hacia ocupaciones no agropecuarias. Entre las cuales se consideraban los servicios que se demandaban alrededor de las agroindustrias, como la reparación de maquinaria, el abastecimiento de agroquímicos y la supervisión técnica en los procesos productivos. Con la expansión de las zonas urbanas y el crecimiento de los desarrollos de viviendas de fines de semana dio lugar al incremento del comercio al por menor, la demanda en servicios de mantenimiento, vigilancia, reparación y transporte (Dirven, 2004).

De acuerdo con las demandas del mercado, las ocupaciones que ofrecían las mejores condiciones laborales, eran para un pequeño grupo de trabajadores especializados que se vincula con métodos de producción que emplean una mayor tecnología, nos referimos a biólogos, agrónomos, reparadores de maquinaria, etc. Y por otro lado, tenemos a un conjunto de ocupaciones que no tendrían las mejores condiciones laborales, estas se refieren a las tareas eventuales relacionadas con la cosecha, empaque y distribución.

Bajo este planteamiento, era de esperarse, que de acuerdo al perfil de la población rural, no toda lograra acceder a empleos que ofrecieran condiciones laborales de calidad. Esto se debe a las restricciones de la calificación de la fuerza de trabajo, por una parte, y por otra, a que no se generó una demanda de empleo debido a que no se observaba un crecimiento en la inversión de las actividades agropecuarias. Esto se debe a que los procesos agroindustriales lograron obtener mayores rendimientos en las mismas superficies, por lo que se consideraron procesos ahorradores de fuerza de trabajo (Grammon \& Lara, 2005).

A raíz de las transformaciones en la economía de las áreas rurales, se ha puesto especial atención, en las últimas décadas, en el estudio de las ocupaciones agrícolas y no agrícolas (Köbrich \& Dirven, 2007; Dirven, 2004, 2002; Berdegué, 2002). En la mayoría de los trabajos se ha podido constatar que no se ofrece una desagregación suficiente de la estructura ocupacional, lo que impide tener un mayor conocimiento sobre la evolución de las ocupaciones en las áreas rurales y sobre sus condiciones laborales. Por lo que en este trabajo se ofrece una mayor desagregación de las ocupaciones y algunos indicadores sobre las condiciones laborales.

Por otra parte, existe un conjunto de trabajos que mencionan que una de las salidas de los hogares rurales de las condiciones de pobreza, se encuentra relacionado con el incremento de las actividades no agropecuarias y de la importancia que pueden tener en la generación de ingresos monetarios, pero desafortunadamente, el acceso a dichas actividades encuentra barreras, ya que la mayor parte de la población no cuenta con la capacitación necesaria para incorporarse en dichas actividades, además de que no existe una oferta amplia de este tipo de ocupaciones.

En el trabajo De Janvry \& Saudelet (2002), se mencionan que las ocupaciones no agrícolas son las que deberían de impulsarse para que la población pobre del campo logre salir de sus condiciones de pobreza. Situación que no queda muy clara del todo, debido a que existen barreras como la escolaridad que impiden que los individuos se inserten en ocupaciones diferentes a las agrícolas. Por otro lado, se tendrían que generar un amplio mercado local y regional pensando en la inserción de la población más joven en actividades no agrícolas.

Estos autores señalan que el nivel de escolaridad mínimo que se debería alcanzar para lograran acceder a dichas actividades medianamente remuneradas es la secundaria completa. Sin embargo, considero que con esa escolaridad difícilmente se pueden insertar en actividades que les permitan acceder a empleos estables y medianamente remunerados, otro factor que no se considera es la eventualidad de las actividades que va en contra de la superación de la pobreza.

Además se ha demostrado que la mayoría de las actividades no agrícolas que se desarrollan en las áreas rurales son precarias, esto se evidencia en el trabajo de Pedrero \& Embriz (1992), cuando se 
aplica el primer módulo agropecuario de la Encuesta Nacional de Empleo en 1988. Menciona que solamente un pequeño grupo de la población rural se inserta en actividades que ofrecen las mejores condiciones laborales y que esto ha sido consistente en trabajos más recientes (Pedrero \& Embriz, 1992; Szász, 1990; Garay, 2008; De Janvry \& Saudelet, 2002).

Como se ha podido observar en esta breve contextualización de las zonas rurales existen diferentes posturas sobre las cuales se abordan las transformaciones en las áreas rurales. Por un lado, se encuentran aquellos que hacen referencia sobre la dinámica económica y sobre los procesos de proletarización en el campo, en el que cada vez se tendría que observar a un mayor número de trabajadores agrícolas asalariados debido a la aparición de las agroindustrias y a la dificultad de los pequeños productores para colocar sus productos en el mercado. Por otro lado, se encuentran a los que ven estas transformaciones como una opción para que los campesinos que se encuentran en condiciones deficitarias mejoren a partir de las actividades no agropecuarias.

\section{El comportamiento de la población económicamente activa rural (PEA-R)}

Las tendencias sobre la participación económica de la fuerza de trabajo rural del país que se observan al revisar el comportamiento de la Población Económicamente Activa (PEA), por grupos de edad y sexo, proporcionará una idea sobre las características de la población que se encuentra en el mercado de trabajo.

El 68,3\% de la población en el año 2000 tenía 12 años y más, 10 años más tarde este conjunto de la población se incrementó aproximado en 5 puntos porcentuales $(73,5 \%)^{4}$, lo que nos indica una mayor proporción de población que potencialmente estaría en condiciones de buscar o desempeñar alguna actividad económica.
En el año 2000 menos de la mitad de la población de 12 años y más era económicamente activa (43,2\%). En este conjunto poblacional se encontraban los que estaban trabajando; los que tenía trabajo y no trabajaron en la semana de referencia; y los que estaban en busca de trabajo. Diez años después, la proporción de este conjunto de la población no presenta cambios sustantivos, ya que la variación entre los dos momentos es pequeña (44,3\%), pero hay que tener presente que aumentó el volumen de la población de 12 años y más. Por lo tanto, a pesar de que no se registran cambios sustantivos en las proporciones de PEA, aumenta la cantidad de fuerza de trabajo disponible que ejercerá presión en el mercado de trabajo.

Como es conocido, la participación en actividad económica en las áreas rurales no se reportan niveles similares a los que se pueden observar en las áreas urbanas. Ese mismo efecto se puede observar en las tasas de participación según sexo. Y como era de esperarse, las tasas más elevadas se presentan entre los varones en comparación con las mujeres, debido a que existen amplias restricciones en el mercado de trabajo y en su vida familiar para este último grupo. En parte se debe a que se les ha delegado la responsabilidad de las tareas domésticas, el cuidado de los miembros del hogar, lo que impide en cierta manera que las mujeres logren incorporarse en actividades extradomésticas y remuneradas (Rendón, 2003; Mummert, 1992).

Esto se puede constatar de manera clara a través de la información desagregada, según sexo. En el año 2000 la tasa de participación económica masculina era $69,1 \%$, considerablemente mayor que la tasa de participación económica femenina de sólo 18,5\%. Esta situación, desafortunadamente no se modifica drásticamente una década después, solamente se aprecian ligeras variaciones $70,8 \%$ y $19,6 \%$ respectivamente. Esto nos continúa hablando de la importancia de la participación de las mujeres en las tareas domésticas como un elemento central de la repro-

4 Debido a la reducción de la fecundidad disminuyeron los grupos iniciales, haciendo que la proporción de los mayores se incrementara. 
ducción de la fuerza de trabajo y la participación de los varones como trabajadores extradomésticos.

Cuando se estiman las tasas específicas de participación económica por edad para mujeres y para hombres, podemos observar que las tasas se elevan considerablemente a partir de los 20 años de edad. En el caso particular de los varones, la mayor participación se encuentra entre los 30 y 39 años de edad; en tanto que en el grupo de las mujeres las tasas de mayor magnitud se encuentran entre los 35 y 44 años de edad. Estas cifras concuerdan con las reportadas por el trabajo de Garay (2008). Lo que nos sugiere que las mujeres maduras, que en general ya no tienen hijos pequeños que cuidar, y por lo tanto, tienen una mayor movilidad en los espacios públicos, se incorporan en tareas extra-domésticas como una forma de contribuir al ingreso familiar.

Hay que recordar que la incorporación de las mujeres en actividades extra-domésticas ha cobrado singular importancia a partir de que los ingresos en los hogares rurales no son los suficientes para la manutención en el hogar, por lo tanto cada vez se ha aceptado en mayor medida esta situación. Esto se puede atribuir a que el ingreso que obtienen los varones no alcanza a cubrir las necesidades del hogar, en tanto que las mujeres buscan mejores condiciones de vida en su hogar (Mummert, 1992; Arias, 2009).

Llama la atención que, tanto para varones como para mujeres, en el año 2010 las tasas específicas de participación económica se incrementan de manera sostenida a partir de los 29 y hasta los 69 años de edad. En sentido opuesto se observa la tendencia de las tasas en los primeros grupos de edad, sobre todo en el grupo de 15 a 19 años, especialmente entre las mujeres. Como se ha podido apreciar, no se modifican sustantivamente las tasas generales de participación económica, pero cuando se examina la información a través de los grupos de edad se identifican cambios en el comportamiento de las tendencias. Se intensifica la participación en ciertos grupos de edad y en las edades más tempranas disminuye. Este comportamiento se puede encontrar asociado con la permanencia de las y los jóvenes en la escuela aunque en el caso de los varones, ya que cerca de la mitad de este grupo se encontraba en el mercado de trabajo (Ilustracion 1).

Ilustración 1. Tasas específicas de participación económica de la población rural de México, según sexo, 2000 y $2010^{5}$

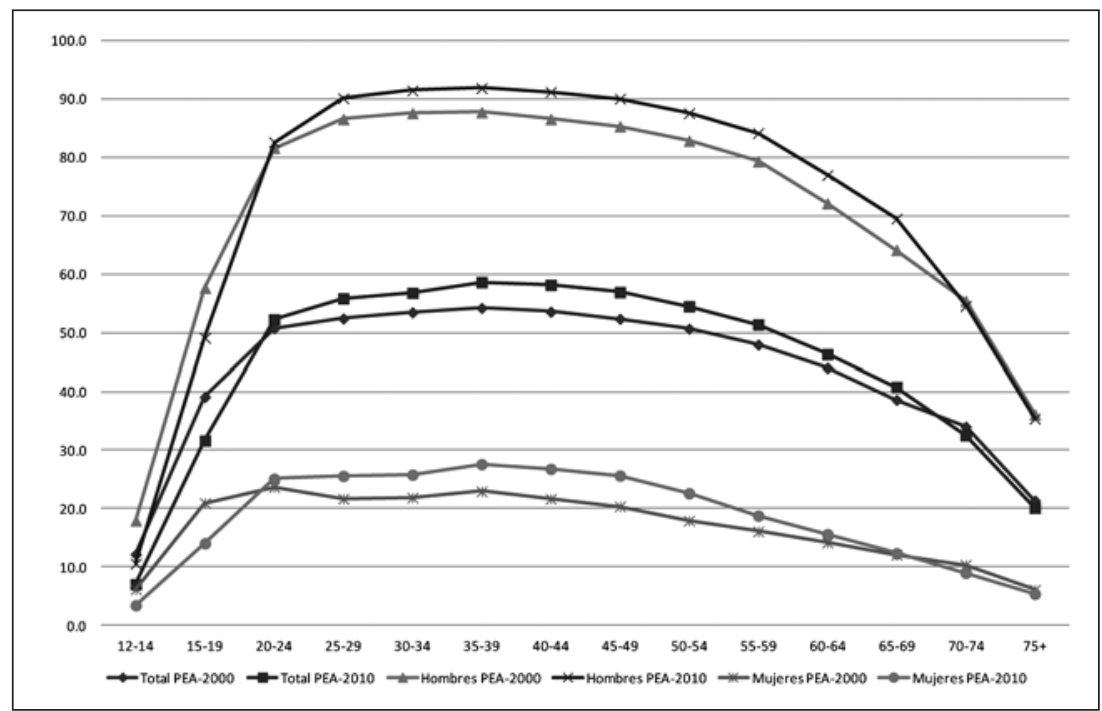

5 Fuente: Imagen de la investigación. 
La inserción temprana de los varones en el mercado laboral se encuentra relacionada con la importancia de la aportación económica al hogar de origen, que además sería una vía para que en el futuro logren fundar un nuevo hogar en el que se convertirán en los principales proveedores de estos hogares. En tanto que las mujeres se encuentran dedicadas principalmente a las ocupaciones familiares y la ruptura de la trayectoria escolar se encuentra asociada al matrimonio (Pacheco Ladrón de Guevara, 2000). Es decir, se continúan reproduciendo los roles de varones proveedores y mujeres dedicadas al hogar, a pesar de que las condiciones económicas cada vez exigen la participación en el mercado de ambos.

El comportamiento de las altas tasas de participación económica de los jóvenes se encuentra relacionada, con la escasez de oferta educativa en el lugar de origen y con el significado de ser un joven en las áreas rurales, ya que se espera que ellos participen en las tareas de apoyo en la agricultura, que se inserten en actividades relacionadas con el comercio y la construcción que son las únicas ofertas laborales que se encuentran en sus lugares de origen (Pacheco Ladrón de Guevara, 2006). Después de hacer este repaso sobre la participación económica de la población rural. A continuación se examinaran las características más relevantes de la población ocupada rural y se presentan los principales cambios en la estructura ocupacional en el periodo de estudio.

\section{Cambios en la estructura ocupacional rural de México}

A pesar de que ya existen estudios sobre las actividades económicas a las que se dedican los habitantes de las áreas rurales, en general, se trabaan como grandes agregados en los que solamente se diferencian las ocupaciones rurales y no rurales. Por lo tanto, no se cuenta con un conocimiento amplio y detallado sobre la estructura ocupacional y las condiciones de trabajo que prevalecen en estas localidades. Es por ello que a lo largo del siguiente apartado se persigue el objetivo de profundizar en las características de las ocupaciones laborales que se encuentra desempeñando la población rural.

La importancia de estudiar la estructura ocupacional de los contextos rurales reside en la dinámica económica por la que ha transitado la población en las últimas décadas de pasar de una sociedad de productores agrícolas a una de trabajadores no agropecuarios de acuerdo con los especialistas en el tema (Saavedra \& Rello, 2010; Grammont, 2009; Appendini \& Torres-Mazuera, 2008; Appendini, 2008 , entre otros). Esto significa que la centralidad en las actividades económicas de los hogares ya no gira en torno a la agricultura como lo era hace algunas décadas.

A continuación mencionaremos algunas características de la población rural. De acuerdo con los datos del Censo General de Población y Vivienda del 2010, la población que se concentraba en áreas rurales en México, en términos relativos representaba el 23,1\% de la población nacional, esto en términos absolutos representaba a un poco más de 26 millones de habitantes, lo que significó un incremento en 1 millón de personas con respecto a los resultados registrados en el Censo de Población y Vivienda del año 2000.

La población ocupada del país en el 2010 ascendió a 42,7 millones de personas, de las cuales, cerca de una quinta parte $(19,0 \%)$ se encontraba en localidades rurales. La población nacional ocupada que se encontraba realizando alguna actividad agrícola, ganadera, forestal de caza y pesca representó alrededor de 4.5 millones (10,6\%), de las cuales, la gran mayoría $(71,5 \%)$ se encontraban en zonas rurales.

Los indicadores que se presentan se construyeron a partir de utilizar como fuente de información los microdatos de la muestra censal del año 2000 y del año $2010^{6}$. La consideración de utilizar esta información se debe en gran medida a la posibilidad de desagre-

6 Debemos mencionar que las fechas en que se levantaron los censo son distintas al del 2000 fue a mitad de mes de febrero y el de 2010 a mitad del mes de junio. Esto puede afectar la comparabilidad de los resultados dada la fuerte estacionalidad de la actividad agrícola. 
gar las ocupaciones sin tener problemas de representatividad, debido a que las muestras son aproximadamente del 10\% del Censo y soportan una desagregación municipal, lo que nos da la posibilidad de trabajar a escalas geollustracions pequeñas.

La población ocupada representó el 29,2\% de la población rural para el año 2000 , lo cual no varió de manera importante 10 años después (30,9\%). Estos ligeros cambios, obedecen a la limitada dinámica y oferta de empleos en el mercado laboral. La permanencia de esta proporción a lo largo del tiempo se debe de examinar con mayor detalle, debido a que se podría haber esperado que la cifra se redujera en lugar de incrementarse o de mantenerse, debido a que la población total de las áreas rurales del país había experimentado descensos en los años iniciales de la primera década de este siglo, por lo que se pronosticaba que esta población disminuiría gradualmente (Esquivel, 2009).

Por otra parte, la población ocupada que se dedicaba a actividades agropecuarias ha disminuido de manera importante, tendencia que se ha mantenido desde mediados de la década de los años ochenta. En el periodo de estudio se registró una disminución aproximadamente de nueve puntos porcentuales (de 57,4\% a 48,9\%, Ilustración 2). Esta tendencia se encuentra en la misma dirección en la que apuntan los resultados de varias investigaciones, tanto a nivel nacional como internacional (Pacheco, 2006; Garay, 2008; Köbrich \& Dirven, 2007; Dirven, 2004, 2002; Berdegué, 2002).

Por lo tanto se puede afirmar que se mantiene la disminución de la proporción de la población rural que se encuentra en ocupaciones agropecuarias. En contraparte, se incrementa la tendencia de la población en ocupaciones no agropecuarias. Una causa se encuentra relacionada con el fin del reparto agrario y que las tierras que tienen los agricultores se fragmentan cada vez más al dividirse entre los hijos como parte de los sistemas de herencias, por lo que no es posible que las nuevas generaciones se sostengan económicamente de la producción agropecuaria.

Otra causa que se puede interpretar es la respuesta de la población frente a la reestructuración econó- mica en el campo mexicano que ha experimentado a lo largo de las últimas décadas, el cual se ha visto afectado directamente por la disminución de la rentabilidad de las tierras debido a su agotamiento, el encarecimiento de los insumos para producir, la escasez de créditos, el bajo rendimiento por hectárea y el bajo precio al que se comercializan los productos.

Cabe señalar que las ocupaciones no agropecuarias han sido un complemento de las actividades agrícolas desde hace tiempo (Szász, 1990; Arias; 2009), y en la actualidad estas actividades se han incrementado e incluso han cobrado mayor centralidad en los ingresos de los hogares rurales (Yúnez \& MeléndezMartínez, 2007; Grammont, 2010), de esta forma, dependen cada vez más de ingresos monetarios, por lo que es relevante examinar dichas ocupaciones de manera detallada.

Al separar la información según sexo, podemos apreciar claramente que las ocupaciones agropecuarias tienen una mayor importancia entre la población masculina en comparación con la población femenina, ya que en el caso del primer conjunto representaba en el año 2000 cerca de dos terceras partes de la población ocupada masculina $(64,2 \%)$ y disminuye en el año 2010 a un poco menos de tres quintas partes $(58,4 \%)$. En el caso de las mujeres representaba un poco más de una cuarta parte de la población ocupada femenina, $26,1 \%$ en 2000 y disminuye casi nueve puntos porcentuales cayendo a $16,9 \%$.

Como se puede apreciar el descenso es menor en el caso de los varones, por lo que continúa siendo una actividad importante. Sin embargo, el descenso que experimenta la población femenina llama la atención ya que en algunos trabajos se había considerado como una participación importante en la agroindustria de exportación, debido a la paciencia, el cuidado y minuciosidad que requerían algunos cultivos en los que se prefirió al trabajo femenino sobre el masculino, además de que presentaban ventajas para estos productores como la adaptabilidad, la aceptación de ingresos más bajos (Roldán, 1982; Arizpe \& Aranda, 1986; Tánori, 1989; Mummert, 1992 y Canales, 1995, citados por Szasz, 1999). 
Además, se ha documentado que el trabajo femenino en la agricultura, sobre todo, en la selección y empaque requiere de una calificación en la que se encuentran con mayor ventaja las mujeres. Estas son algunas razones por las que se esperaría que las ocupaciones agropecuarias se expandieran o se mantuvieran entre la población femenina. Lo que no se refleja en la información que revisamos.

Estas cifras nos indican que las mujeres mantienen una tendencia en descenso en la inserción en ocupaciones agrícolas, tendencia que se había mencionado que iba en sentido inverso. De acuerdo con trabajos como el de Lastarria-Cornhiel (2008), en el que se menciona una mayor participación de la fuerza de trabajo femenina en la agricultura asalariada y en la pequeña agricultura, por lo que se tendría que matizar en qué sectores se presenta una feminización de la agricultura.

La información de las muestras censales de México indica una tendencia en que las mujeres cada vez más se insertan en actividades no agropecuarias y que los varones son los que se mantienen en las actividades agropecuarias. Estos resultados se encuentran más cercanos a lo que menciona el trabajo de Arias (2009), en el que destaca, que la participación económica de las mujeres históricamente se ha vinculado con ocupaciones no agropecuarias, en el comercio al por menor, la elaboración de artesanías y de algunos alimentos, que ha sido una forma de obtener ingresos monetarios para el hogar.

Como se ha podido observar la población ocupada que se encontraba desempeñando actividades agropecuarias ha descendido, es una tendencia que se esperaba, pero este descenso se ha manifestado de distintas formas para mujeres y hombres.

Por otro lado, la proliferación de las actividades no agropecuarias se manifiesta como una respuesta de los individuos en el afán de procurarse alguna actividad económica que les permita ganarse la vida, situación que es compleja debido a las limitadas oportunidades que ofrece el mercado laboral y, el dedicarse a estas actividades no necesariamente significa que hayan mejorado sus condiciones laborales.
Cuando se revisa la estructura ocupacional del año 2000 se puede observar que las principales ocupaciones que continúan absorbiendo a gran parte de la población rural son las actividades agropecuarias, ya que son las que mantienen las proporciones más elevadas, como es el caso de la población ocupada que se dedicaba al cultivo del maíz y fríjol, a pesar de que ha disminuido su presencia relativa en el periodo de estudio (19,6\% y 16,1\%); seguida de otros cultivos agrícolas (11,3\% a 9,5\%); otras actividades agrícolas no clasificadas (7,3\% a 6,4\%); y la ganadería, cría de animales (7,3\% a 7,0\%).

Entre las principales ocupaciones no agropecuarias se encuentra el comercio y los empleados en ventas (de 5,4\% a 7,8\%), los albañiles, mamposteros y afines (de 4,0\% a 5,2\%), el trabajo doméstico (de 3,9\% a $2,8 \%)$ y los conductores de vehículos de carga y pasajeros (de 1,9\% a 2,9\%). Como se puede observar las ocupaciones mencionadas anteriormente no requieren de un nivel de capacitación formal elevado sino que sus habilidades las adquieren con la experiencia y se podría decir que son ocupaciones que, en términos generales, no ofrecen las mejores condiciones laborales.

Las ocupaciones con más calificación formal son las que representan los menores porcentajes de la población ocupada, pero no por ello dejan de tener importancia, ya que aumentan los ocupados como técnicos $(3,2 \%$ a $5,9 \%)$ y profesionistas $(1,4 \%$ a $2,7 \%)$. Este ligero incremento puede obedecer a la ampliación de la oferta de trabajo especializado y calificado que se requiere en la agroindustria (Tabla 1 ).

Esta información se encuentra en el sentido esperado, ya que se ha mencionado en algunos trabajos que las principales ocupaciones no agropecuarias que aumentarían serían las menos calificadas, como consecuencia de restricciones que existen en la calificación de la mano de obra rural, que en general cuenta con bajos niveles de escolaridad.

Algunas evidencias señalan que para obtener empleos que ofrezcan mejores condiciones laborales, la población por lo menos tiene que haber alcanzado el nivel de educación media superior (Yúnez-Naude 
Tabla 1. Distrbución de la población ocupada en las áreas rurales de México 2000 y 20107

\begin{tabular}{|c|c|c|c|c|c|c|}
\hline & \multicolumn{2}{|c|}{ Hombre } & \multicolumn{2}{|c|}{ Mujeres } & \multicolumn{2}{|c|}{ Total } \\
\hline & 2000 & 2010 & 2000 & 2010 & 2000 & 2010 \\
\hline T. en el cultivo de maíz y o frijol & 23.7 & 19.6 & 5.0 & 4.4 & 19.6 & 16.1 \\
\hline T.en el cultivo de hortalizas, verduras, frutas y flores & 6.9 & 8.4 & 4.6 & 2.4 & 6.4 & 7.0 \\
\hline O.T. en actividades agricolas no clasificadas & 8.8 & 8.0 & 1.7 & 1.1 & 7.3 & 6.4 \\
\hline T. en otros cultivos agricolas & 12.0 & 11.2 & 9.1 & 3.9 & 11.3 & 9.5 \\
\hline T. en actividades ganaderas y cría de animales & 8.1 & 7.8 & 4.6 & 4.4 & 7.3 & 7.0 \\
\hline T. en actividades pesqueras forestales, caza y similares & 4.7 & 3.3 & 1.1 & .7 & 3.9 & 2.7 \\
\hline Funcionarios, directores y jefes & .7 & .7 & .9 & 1.0 & .8 & .8 \\
\hline Profesionistas & 1.0 & 1.8 & 2.8 & 5.8 & 1.4 & 2.7 \\
\hline Técnicos & 1.4 & 2.9 & 4.1 & 4.3 & 2.0 & 3.2 \\
\hline T. auxiliares en actividades administrativas & 1.0 & .9 & 4.4 & 4.7 & 1.8 & 1.8 \\
\hline Comerciantes, empleados en ventas y agentes de ventas & 3.3 & 4.2 & 13.0 & 19.8 & 5.4 & 7.8 \\
\hline T. en la preparación y servicio de alimentos y bebidas & .6 & .9 & 3.1 & 7.3 & 1.2 & 2.4 \\
\hline T. en servicios personales y vigilancia & 1.5 & 2.7 & 6 & 2.7 & 1.3 & 2.7 \\
\hline Albañiles mamposteros y afines & 5.1 & 6.7 & 1 & .1 & 4.0 & 5.2 \\
\hline T. en la extracción y edificaciones de construcciones & 1.2 & 1.2 & 1 & .1 & .9 & .9 \\
\hline T. de apoyo en la construcción & 3.9 & 4.2 & .2 & .2 & 3.1 & 3.2 \\
\hline A. y T. en en el tratamiento de productos de metal, madera, papel & 2.9 & 2.2 & 1.2 & 1.5 & 2.5 & 2.1 \\
\hline A. y T. en la elaboración de productos textiles & .7 & .5 & 5.7 & 4.4 & 1.8 & 1.4 \\
\hline T. en la preparación de alimentos, bebidas y productos de tabaco & .9 & 1.3 & 5.3 & 5.1 & 1.9 & 2.2 \\
\hline A. y T. en productos de hule. plástico sustancias químicas y cerámica & 2.1 & 1.1 & 1.6 & 1.0 & 1.9 & 1.1 \\
\hline Operadores de maquinaria industrial, ensambladores & 2.1 & 2.2 & 5.4 & 3.8 & 2.8 & 2.6 \\
\hline Conductores de transporte y maquinaria móvil & .7 & 1.0 & .0 & .3 & 6 & .9 \\
\hline Conductores de camiones de carga y de pasajeros & 2.4 & 3.7 & .0 & .1 & 1.9 & 2.9 \\
\hline Vendedores ambulantes & .8 & .9 & 2.4 & 3.7 & 1.1 & 1.6 \\
\hline Trabajadores domésticos & .2 & .1 & 17.3 & 11.5 & 3.9 & 2.8 \\
\hline T. de limpieza, de paquetería y repartidoeres de mercancías & 1.8 & 1.7 & 2.4 & 4.6 & 1.9 & 2.3 \\
\hline \multirow[t]{3}{*}{ Ocupaciones no específicadas } & 1.5 & .7 & 3.3 & 8 & 1.9 & .7 \\
\hline & 100.0 & 100.0 & 100.0 & 100.0 & 100.0 & 100.0 \\
\hline & $\overline{5,618,548}$ & 250,054 & $\overline{563,812}$ & 884,953 & 182,360 & $1,135,007$ \\
\hline
\end{tabular}

\& Taylor, 2001), o para acceder a actividades no agropecuarias la población por lo menos debería alcanzar 9 años de escolaridad (De Janvry \& Saudelet, 2002), lo cual excluye a un amplio sector de la población rural, sobre todo a la generación más antigua, debido a los bajos niveles de escolaridad logrados. Otra restricción es la limitada oferta de empleos que ofrezcan las mejores condiciones laborales, de tal suerte que las ocupaciones que han aumentado se relacionan con el autoempleo, como la albañilería y el comercio.

Las tres principales actividades a las que los varones se dedicaban era el cultivo de maíz y frijol, otros cultivos agrícolas y la ganadería o cría de animales; que mantienen su importancia 10 años después y, llama la atención el incremento de la participación de los varones en ocupaciones vinculadas con el cultivo de hortalizas, frutas, verduras y flores. Este comportamiento es similar a las tendencias generales de la población ocupada y con esto podemos confirmar que la expansión de estas ocupaciones se presentó entre los varones más que en el caso de las mujeres; es importante mencionar que en el periodo de estudio la proporción de mujeres en esta actividad desciende. Este dato nos podría indicar que la fuerza de trabajo masculina se encuentra compitiendo por ocupaciones en que las mujeres tenían una presencia importante, como una respuesta frente a las limitadas oportunidades que se ofrecen en el mercado laboral.

En el caso de las mujeres las tres principales actividades que desempeñaban en el año 2000 fueron el trabajo doméstico, el comercio y las empleadas en ventas; diez años más tarde el comercio y las

7 Fuente: Cálculos propios a partir de la Muestra del Censo de Población y Vivienda del 2000 y 2010. 
empleadas en ventas ocupan la actividad predominante; seguidas del trabajo doméstico, que disminuye su proporción en el periodo de estudio; y la preparación y servicios de alimentos y bebidas. Esta información confirma que las mujeres se insertan predominantemente en ocupaciones no agropecuarias (Garay, 2008; Arias, 2009). Al contrario de lo que ocurre en el caso de los varones en los que las ocupaciones agropecuarias continúan siendo una fuente importante de empleo.

Para enfatizar estas diferencias y mostrar con mayor claridad las distribuciones, a continuación se separa la población ocupada en ocupaciones agropecuarias y no agropecuarias, por lo que las proporciones se estimarán con respecto a cada subconjunto, de esta manera se ilustrarán el peso de las ocupaciones a nivel nacional y regional.

\subsection{Ocupaciones agropecuarias}

Las tres principales ocupaciones dentro de las actividades agropecuarias en el año 2000 se refieren al cultivo de maíz y frijol $(35,1 \%)$, otros cultivos agrícolas $(20,3 \%)$ y la ganadería (13,1\%). Diez años más tarde el cultivo de maíz se mantiene como la principal ocupación a pesar de que disminuye ligeramente (33,0\%);lo mismo ocurre en los trabajadores en otros cultivos agrícolas (19,5\%); en el caso de la ganadería (14,4\%) aumenta ligeramente al igual quelos trabajadores en el cultivo de hortalizas, verduras, frutas y flores (14,4\%), (Ilustración 2). Los ocupados que comprenden a los trabajadores en otros cultivos cuentan con una vasta proporción de ocupacionesde apoyo que nos sugieren las condiciones laborales deficitarias a las que se puede estar enfrentando la población rural en la actualidad, es decir que las actividades asalariadas agropecuarias se continúan precarizando (Lara, 2011).

Al distinguir la información según sexo, observamos que los varones presentan las tendencias que se mostraron en el párrafo anterior; mostrando su presencia principalmente en el cultivo de maíz y fríjol (de $36,7 \%$ a $33,6 \%^{8}$ ); en otros cultivos agrícolas (de
$18,7 \%$ a $19,2 \%)$ y, los trabajadores que aumentan se encuentran en el cultivo de hortalizas, verduras y flores (de $10,7 \%$ a $14,4 \%{ }^{9}$ ). Estos resultado fortalecen el argumento de que los varones se han desplazado dentro de las actividades agropecuarias hacia mercados en los que no se observaba una participación elevada, tal vez hayan entrado en competencia con las mujeres en los cultivos de exportación.

A pesar de que las actividades agroindustriales han necesitado en principio de una fuerza de trabajo de jornaleros que no se encontraba en la región, por lo que algunos campesinos que se encontraban en condiciones de pobreza son los que migraban a los campos de cultivo; en un inicio principalmente los varones y eran trabajos temporales, pero después se observaron familias completas que acudían a estos lugares de trabajo (Grammont \& Lara, 2005), que se encuentra relacionado con la forma en que se produce en la actualidad, en la que las agroindustrias prácticamente pueden producir todo el año.

Y también llama la atención que las actividades de cultivo de granos básicos se ha mantenido más o menos de forma regular dentro de la distribución de las ocupaciones agropecuarias, es decir, hay un conjunto de la población que continúa produciendo en pequeña escala para su autoconsumo. Situación que podría resultar la más probable, de acuerdo con las transformaciones económicas que se han dado en campo recientemente.

La principal ocupación agropecuaria para las mujeres en el año 2000 se concentraba en otros cultivos agrícolas (34,7\%), seguidas del cultivo de maíz y frijol $(19,1 \%)$, y al cultivo de hortalizas, frutas, verduras y flores (17,8\%). Situación que se transforma considerablemente diez años después ya que la ocupación que tiene una mayor presencia es el cultivo de maíz y frijol (26,4\%), en la ganadería y la cría de animales $(25,8 \%)$ y en otros cultivos agrícolas $(22,8 \%)$. Como se muestra, desaparece la importante presencia femenina en el cultivo de hortalizas, frutas, verduras y flores, esto nos podría sugerir que las mujeres se han desplazado hacia otras actividades.

\footnotetext{
8 Estos cambios significan que se pasa de 1.3 millones a 1.2 millones de varones ocupados en dichos cultivos

9 Estos cambios en números absolutos significa que se pasa de 391 mil a 527 mil ocupados en dichos cultivos.
} 
Como ejemplo, en el caso del cultivo del maíz en el año 2000 no se tenía una proporción elevada, que posteriormente se incrementa notablemente, (véase Ilustración 2). Es decir, las mujeres que se dedicaron a actividades agropecuarias prácticamente se encontraban en el cultivo de granos básicos.

Además, estas ocupaciones, en términos generales, hacen referencia al trabajo por cuenta propia y a los cultivos de subsistencia; una situación similar ocurre en el caso de la cría de animales, en el que se encuentran contempladas las pequeñas especies que se encuentran en el solar de las viviendas y que se destinan al consumo del hogar y no al comercio.

Por otra parte, el trabajo agrícola asalariado se encuentra en mayor medida en el cultivo de hortalizas, frutas y flores que desciende en el periodo de estudio. Esto significa que el trabajo en las agroindustrias tiene un límite en la absorción de la fuerza de trabajo.
Además, las agroindustrias se han caracterizado por sus procesos ahorradores de mano de obra y a su vez han logrado aumentar la productividad por hectárea (Grammont \& Lara, 2005).

Es necesario mencionar que en México, existe una diferenciación regional con respecto al desarrollo de las actividades agropecuarias, que se ha mantenido históricamente, en el que se observa mayor productividad en las regiones ${ }^{10}$ del Norte, Noreste y Noroeste, a diferencia de las regiones del Sur y Golfo en el que los procesos productivos agropecuarios tienen menores rendimientos, lo que nos sugiere condiciones distintas en los mercados de trabajo.

Cuando se revisa la distribución de las ocupaciones de la población de acuerdo a la región geollustracion, se puede identificar de manera clara que para el año

Ilustración 2. Distribución porcentual de la población ocupada rural de México en ocupaciones agropecuarias, según sexo 2000 y $2010 .{ }^{11}$

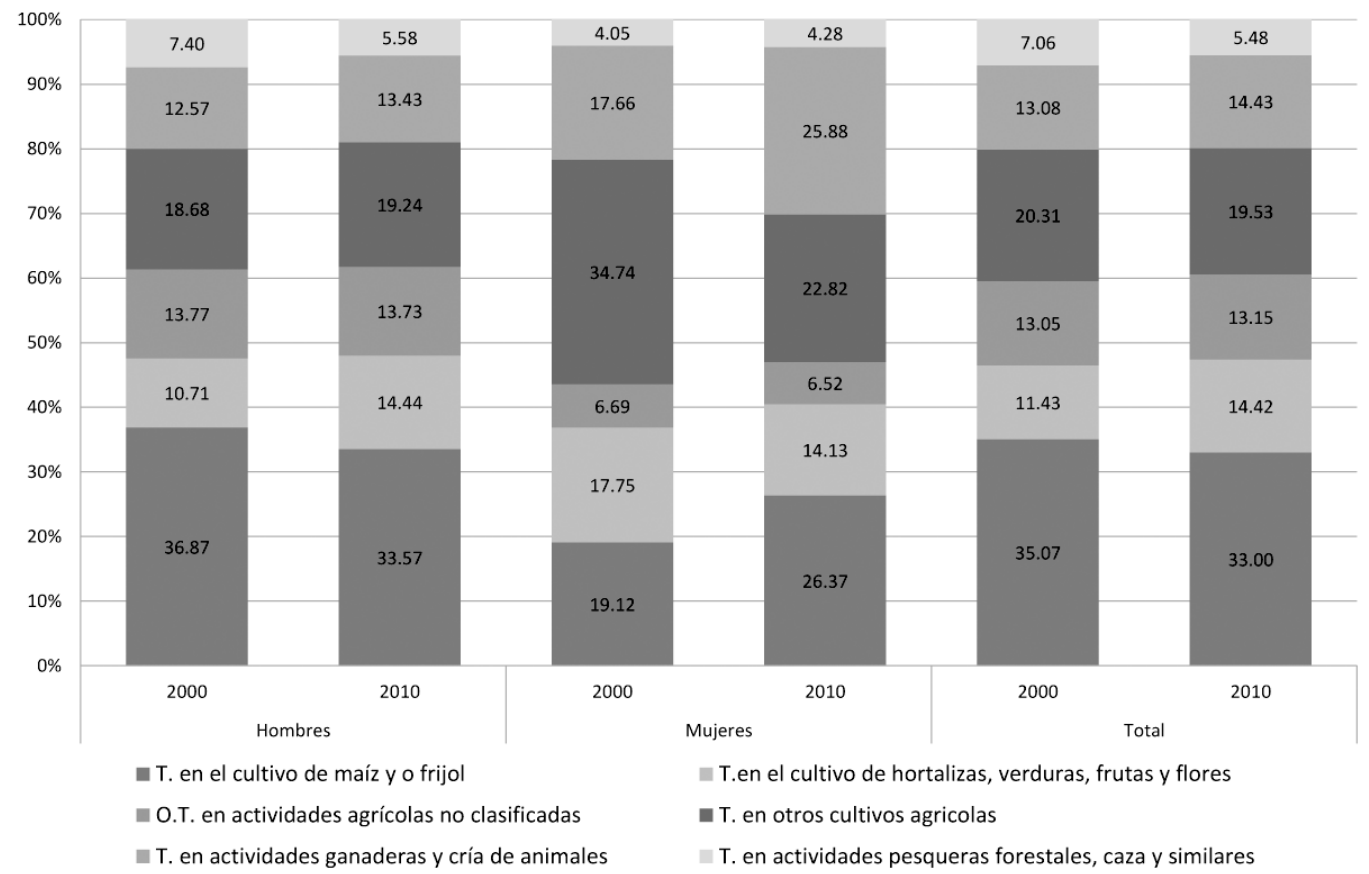

10 Sobre este tema se pueden revisar los trabajos de Appendini (1976) y Florez (2011).

11 Fuente: Elaboración propia. 
2000, las proporciones de personas que se dedicaban a actividades agropecuarias se concentraban en el cultivo de maíz y fríjol, sobre todo en la región Centro, Sur, Golfo y Península, esta tendencia ha manteniendo su importancia en el 2010 (Tabla 2). Sin embargo, en la región Sur, se incrementa el porcentaje de la población ocupada en dichas ocupaciones $y$, en sentido contrario se observan las tendencias de las otras tres regiones mencionadas que han mostrado tendencias que van en descenso.

La población en el cultivo de hortalizas ha mantenido comportamientos no esperados, ya que en el año 2000 se encontraba principalmente en la región Noroeste y Occidente, lo que no ocurre para el año 2010, en el que se aprecia una pérdida en la importancia relativa en la estructura ocupacional de la población y, cobran una mayor importancia relativa en las regiones del Occidente, Golfo, Sur, Centro y Centro Norte (Tabla 2).

La ganadería en el año 2000 mostraba importancia para la región Norte, Noreste y Centro-Norte, que concentraban a parte importante de la población ocupada dentro de las actividades agropecuarias. Sin embargo, en el año 2010 experimen- taron una disminución de manera considerable y, a pesar de ello, continuaron siendo las regiones que concentraban a la mayor cantidad de población ocupada en la cría de ganado.

En la Tabla 2 se observa que los varones el cultivo en maíz y fríjol tiene una mayor importancia en la región Sur, Centro y Península, lo que continua indicándonos la importancia de estas actividades para gran parte de la población masculina. Esta situación es diferente en la región Noroeste en la que se incrementa la participación masculina en el cultivo de hortalizas, frutas y verduras.

Debemos mencionar que en esta región se encuentran las grandes agroindustrias, lo que nos sugiere que estas actividades son asalariadas, caso contrario que ocurre en el primer conjunto de regiones en el que los principales cultivos son granos básicos y que posiblemente se destinen para el consumo del hogar.

Por otro lado, cuando se revisa a la población ocupada femenina, se puede observar que en la región Noroeste se presentó el mayor descenso en el cultivo de hortalizas, frutas y verduras y solamente en la región Occidente se mantuvo.

Tabla 2. Distribución de la pobalción ocupada en actividades agropecuarias por región y sexo, 2000 y 2010.12

\begin{tabular}{|c|c|c|c|c|c|c|c|c|c|c|c|c|c|c|c|c|c|c|}
\hline \multirow[b]{3}{*}{ Hombres } & \multicolumn{18}{|l|}{ Región } \\
\hline & \multicolumn{2}{|c|}{ Noroeste } & \multicolumn{2}{|c|}{ Norte } & \multicolumn{2}{|c|}{ Noreste } & \multicolumn{2}{|c|}{ Occidente } & \multicolumn{2}{|c|}{ Centro Norte } & \multicolumn{2}{|c|}{ Centro } & \multicolumn{2}{|c|}{ Sur } & \multicolumn{2}{|c|}{ Golfo } & \multicolumn{2}{|c|}{ Peninsula } \\
\hline & 2000 & 2010 & 2000 & 2010 & 2000 & 2010 & 2000 & 2010 & 2000 & 2010 & 2000 & 2010 & 2000 & 2010 & 2000 & 2010 & 2000 & 2010 \\
\hline T. en el cultivo de maiz y o frjol & 11.6 & 5.0 & 18.2 & 15.8 & 21.6 & 9.3 & 32.0 & 182 & 28.4 & 17.7 & 44.9 & 38.4 & 46.0 & 56.7 & 37.4 & 27.9 & 50.8 & 44.0 \\
\hline T.en el cuttivo de hortalizas, verduras, frtas y sores & 36.0 & 7.4 & 7.9 & 10.9 & 8.4 & 7.4 & 16.5 & 23.4 & 11.7 & 13.8 & 82 & 15.8 & 5.1 & 10.8 & 9.9 & 18.7 & 6.7 & 9.8 \\
\hline O.T. en actividades agricolas no clasi & 15.6 & 72 & 23.2 & 17.7 & 21.6 & 122 & 16.7 & 15.4 & 19.3 & 16.1 & 13.4 & 15.7 & 9.5 & 12.4 & 11.5 & 12.7 & 11.6 & 11.9 \\
\hline T. en otros cultivos agricolas & 5.4 & 45.6 & 7.7 & 23.5 & 9.5 & 36.3 & 10.1 & 19.4 & 13.4 & 29.6 & 20.0 & 16.6 & 26.3 & 9.0 & 25.2 & 21.3 & 6.1 & 9.5 \\
\hline T. en actividades ganaderas y cria de animales & 17.1 & 21.5 & 31.3 & 25.8 & 23.9 & 24.4 & 16.0 & 18.4 & 22.5 & 20.0 & 9.3 & 9.6 & 5.6 & 5.8 & 10.0 & 13.4 & 13.4 & 16.5 \\
\hline \multirow[t]{3}{*}{ T. en actividades pesqueras forestales, caza y similares } & 14.2 & 13.3 & 11.7 & 62 & 14.9 & 10.4 & 8.6 & 5.2 & 4.7 & 2.9 & 42 & 3.9 & 7.4 & 5.3 & 6.0 & 6.1 & 11.4 & 8.2 \\
\hline & 100.0 & 100.0 & 100.0 & 100.0 & 100.0 & 100.0 & 100.0 & 100.0 & 100.0 & 100.0 & 100.0 & 100.0 & 100.0 & 100.0 & 100.0 & 100.0 & 100.0 & 100.0 \\
\hline & 228,945 & 180.520 & 153,927 & 188.292 & 102,877 & 98,032 & 396,509 & 408,610 & 378,583 & 430,310 & 604,213 & 586,743 & 940,215 & $1,020,609$ & 687,911 & 627,788 & 112,392 & 109.518 \\
\hline \multicolumn{19}{|l|}{ Mujeres } \\
\hline T. en el cultivo & 1.9 & 5 & 15.1 & 8.1 & 11.3 & 6.8 & 19.4 & 8.0 & 14.3 & 9.1 & 18.2 & 26.7 & 25.4 & 48.8 & 17.6 & 20.6 & 35.9 & 21.5 \\
\hline hortalizas, verduras, frutas y sores & 84.1 & 7.7 & 20.2 & 15.1 & 21.7 & 10.1 & 34.6 & 30.2 & 28.7 & 19.7 & 10.3 & 14.5 & 4.6 & 7.2 & 7.1 & 15.4 & 17.3 & 10.7 \\
\hline O.T. en & 4.8 & 3.0 & 11.9 & 8.6 & 8.2 & 7.5 & 8.4 & 6.7 & 11.1 & 6.6 & 6.2 & 8.2 & 6.9 & 5.9 & 4.2 & 5.7 & 9.9 & 5.4 \\
\hline T. en otro & 5 & 71.0 & 1.4 & 36.7 & 8.0 & 34.4 & 7.8 & 23.0 & 6.4 & 30.7 & 41.5 & 17.5 & 42.7 & 12.6 & 59.7 & 21.1 & 8 & 16.6 \\
\hline T. en actividades ganaderas y cria de & 4.5 & 122 & 46.3 & 28.4 & 39.3 & 29.8 & 24.1 & 27.1 & 35.0 & 30.8 & 21.1 & 29.1 & 15.5 & 22.0 & 8.8 & 30.3 & 31.4 & 40.8 \\
\hline \multirow[t]{3}{*}{ T. en actividades pesqueras forestales, caza y similares } & 4.2 & 5.7 & 5.0 & 32 & 11.5 & 11.4 & 5.7 & 4.9 & 4.4 & 3.1 & 2.7 & 4.0 & 4.9 & 3.5 & 2.6 & 7.0 & 4.6 & 5.0 \\
\hline & 100.0 & 1000 & 100.0 & 100.0 & 100.0 & 100.0 & 100.0 & 100.0 & 100.0 & 100.0 & 100.0 & 100.0 & 100.0 & 1000 & 100.0 & 100.0 & 100.0 & 100.0 \\
\hline & 36,116 & 21,178 & 5,794 & 11,043 & 3,323 & 4,017 & 29,203 & 36,929 & 29,813 & 36,380 & 92,537 & 75,216 & 142,335 & 101,963 & 63,004 & 27,483 & 5,314 & 3.869 \\
\hline \multicolumn{19}{|l|}{ Total } \\
\hline $\bar{T}$ T.enelc & 10.3 & 4.5 & 18.1 & 15.3 & 21.3 & 92 & 31.2 & 17.3 & 27.3 & 17.0 & 41.3 & 37 & 43.3 & 56.0 & 35.7 & 27.6 & 50.2 & 432 \\
\hline T.enela & 42.6 & 7.4 & 8.3 & 112 & 8.8 & 7.5 & 17.8 & 23.9 & 13.0 & 14.3 & 8.5 & 15.7 & 5.0 & 10.5 & 9.7 & 18.5 & 7.2 & 9.9 \\
\hline O.T. en & 14.2 & 6.7 & 22.8 & 172 & 21.2 & 12.1 & 16.2 & 14.7 & 18.7 & 15.3 & 12.5 & 14.8 & 9.2 & 11.8 & 10.9 & 12.4 & 11.5 & 11.7 \\
\hline T. en otr & 4.7 & 48.3 & 7.5 & 24.3 & 9.5 & 36.3 & 9.9 & 19.7 & 12.9 & 29.7 & 22.9 & 16.7 & 28.5 & 9.3 & 28.1 & 21.3 & 5.8 & 9.8 \\
\hline T. en actividades ganaderas y cria de arimales & 15.4 & 20.6 & 31.8 & 26.0 & 24.4 & 24.6 & 16.6 & 192 & 23.4 & 20.8 & 10.8 & 11.8 & 6.9 & 7.3 & 9.9 & 14.1 & 14.2 & 17.4 \\
\hline \multirow[t]{2}{*}{ T. en actividades pesqueras forestales, caza y similares } & 12.8 & 12.5 & 11.5 & 6.1 & 14.8 & 10.5 & 8.4 & 5.2 & 4.7 & 2.9 & 40 & 3.9 & 7.1 & 5.2 & 5.7 & 6.1 & 11.1 & 8.1 \\
\hline & 100.0 & 1000 & 100.0 & 100.0 & 100.0 & 100.0 & 100.0 & 100.0 & 100.0 & 100.0 & 1000 & 100.0 & 100.0 & 100.0 & 100.0 & 100.0 & 100.0 & 100.0 \\
\hline
\end{tabular}

12 Fuente: Cálculos propios a partir de la Muestra del censo de población y vivienda del 2000 y 2010. 
En la región Sur se incrementa la participación de las mujeres que se dedican al cultivo de granos básicos. Lo que nos sugiere que los procesos de participación de la mano de obra femenina se presentan de manera diferenciada entre las regiones. Otra situación que llama la atención es el notable incremento de la población femenina en otros cultivos agrícolas en la en la región Noroeste y Norte, posiblemente se refieren a ocupaciones asalariadas (Tabla 2).

Con la información que se ha presentado hasta aquí, se puede decir que el proceso de feminización de la agricultura o del trabajo agrícola no se distingue de manera clara a nivel nacional, ya que por el contrario, existe una amplia participación masculina y solamente en algunas regiones se ha observado una mayor participación de las mujeres en estas ocupaciones.

\subsection{Ocupaciones no agropecuarias ${ }^{13}$}

Después de revisar detalladamente las distribuciones de las ocupaciones agropecuarias, a continuación se presenta una revisión similar para las actividades no agropecuarias. Entre las principales ocupaciones que manifestaron un aumento se encuentran los comerciantes y empleados (de $12,8 \%$ a $15,5 \%$ ), los trabajadores en la construcción (de 11,6\% a 17,4\%) y las ocupaciones calificadas (de 9,3\% a 13,2\%). En contraparte, las ocupaciones que experimentaron un descenso se encuentra en el trabajo doméstico (de 9,3\% a 5,5\%), los artesanos y trabajadores en la industria (de $26,0 \%$ a $18.6 \%$ ). Con estos datos se confirma la tendencia en descenso de las ocupaciones relacionadas con las actividades industriales. Esto se relaciona con los problemas que ha experimentado el sector industrial en los últimos años. Por lo que se han visto afectadas las actividades para las mujeres en el trabajo textil que han sido una fuente importante de empleo para las mujeres en algunas áreas rurales de México (Arias, 1995).

Y por otro lado, llama la atención el descenso de la población ocupada femenina que se dedicaba al trabajo doméstico, ocupación en la que se habían insertado las mujeres de forma tradicional. Este descenso puede obedecer a que las mujeres jóvenes

Ilustración 3. Distirbución porcentual de la población ocupada rural de México eno cupaciones no agropecuarias, según sexto, 2000 y 2010. ${ }^{14}$

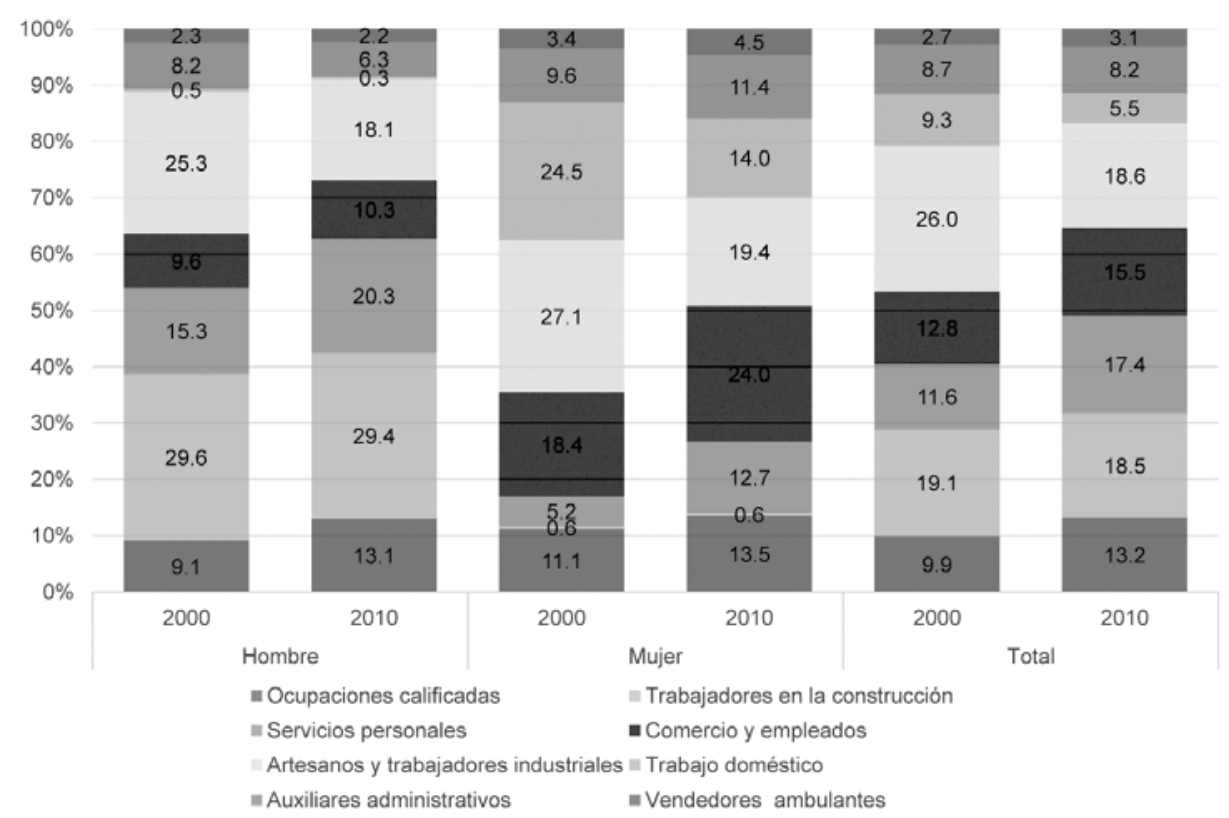

13 Debido a que la información sobre la estructura ocupacional no agropecuaria cuenta con una vasta categorización, nos dimos a la tarea de hacer una simplificación para revisar la información por región. La forma en que se reagrupa aparece en la tabla 3.

14 Fuente: Elaboración propia. 
con mayor escolaridad se hayan incorporado en ocupaciones como empleadas en comercios; y que las mujeres adultas con hijos se hayan incorporado en ocupaciones como la venta y preparación de alimentos que les permite combinar el trabajo extradoméstico con el trabajo doméstico y de cuidado de los miembros de la familia.

Por otra parte, las ocupaciones calificadas aumentan ligeramente. Este incremento se puede asociar a la demanda de servicios que requieren de una mayor calificación en los servicios productivos a las agroindustrias, pero también se tiene que considerar la posibilidad de que el trabajo se realiza en lugares distintos al de residencia. Por ejemplo la cercanía con zonas urbanas con eficientes vías de comunicación que permiten el traslado cotidiano; la expansión de los desarrollos de fines de semana que se han construido en algunas áreas rurales demandan un conjunto de servicios como de mantenimiento, vigilancia, transporte y comercio (Dirven, 2002, 2004).

La información que se refiere a la población ocupada masculina sigue un patrón similar al comportamiento de la población total ocupada rural, debido al peso que mantiene en la estructura ocupacional. Por lo tanto, se apreciar el incremento de los trabajadores en la construcción, en los servicios personales y en las ocupaciones calificadas. En contra parte, las ocupaciones que descienden se encuentran entre los artesanos y trabajadores en la industria.

Las principales actividades en que se encontraban las mujeres ocupadas en el año 2000 fueron: el trabajado doméstico, el comercio, las artesanas y trabajadoras industriales. Diez años después, la mano de obra femenina se concentra en las empleadas en el comercio, las trabajadoras domésticas, las trabajadoras en servicios personales. El incremento en las actividades comerciales se puede asociar a que estas ocupaciones en las que se están insertando las mujeres son actividades informales (García \& Oliveira, 1998) y, por lo tanto, que sus condiciones laborales son deficitarias con bajos niveles de remuneración. Una de las ocupaciones que experimentó un descenso importante fueron las artesanas y trabajadoras en la industria, que habían sido un grupo importante en el que se habían incorporado las mujeres y que al parecer han transitado por situaciones muy desalentadoras en los últimos años.
Al revisar la información por regiones podemos observar que las actividades no agropecuarias en el año 2000 mantenían proporciones semejantes entre la mayoría de regiones y principalmente se encontraba la población ocupada desempeñando actividades relacionadas con el comercio, principalmente en la región Occidente y Golfo que se incrementan en el periodo de estudio (Tabla 3).

La población dedicada a la construcción en el año 2000 representaba una de las ocupaciones más importantes, como se manifestaba de manera clara entre todas las regiones, entre las que destacan la región Centro-Norte y la región Centro; este sector se ha mantenido con una proporción semejante para el año 2010 (Tabla 3), solamente se han podido apreciar ligeras fluctuaciones, a pesar de ello siguen siendo una actividad no agropecuaria que ha mantenido su importancia a lo largo del periodo de estudio.

El trabajo doméstico es una de las ocupaciones no agropecuarias que tienen una importancia relativa a lo largo de todas las regiones, ya que ha sido una actividad que ha absorbido a contingentes importantes de la población ocupada femenina, sobre todo destacan principalmente la población ocupada en la región Península, Sur y Golfo. Sin embargo, se advierte que esta es una de las actividades que ha disminuido en los últimos 10 años (Tabla 3).

La importancia de los artesanos y trabajadores en la industrial en el año 2000 se manifestaba de manera clara en tres regiones principales: el Norte, Noroeste y Centro Norte, que 10 años después disminuyen su presencia, por lo que se podría decir que han tenido una contracción las actividades industriales en las áreas rurales del país y, las actividades que se han incrementado han sido las relacionadas con el comercio principalmente, en menor medida en los servicios y la construcción.

Finalmente, dentro de las actividades no agropecuarias es necesario mencionar el comportamiento y la evolución de las ocupaciones con mayor calificación, que en la estructura ocupacional representan las proporciones menores de la población ocupada, sobre todo en las regiones del Golfo, Sur y Occidente en comparación con el resto de las 
Cuadro 3. Distribución de la población ocupada en actividades no agropecuarias por región y sexo, 2000 y $2010^{15}$

\begin{tabular}{|c|c|c|c|c|c|c|c|c|c|c|c|c|c|c|c|c|c|c|}
\hline \multirow[b]{2}{*}{ Hombres } & \multicolumn{2}{|c|}{ Noroeste } & \multicolumn{2}{|c|}{ Norte } & \multicolumn{2}{|c|}{ Noreste } & \multicolumn{2}{|c|}{ Occidente } & \multicolumn{2}{|c|}{ Centro Norte } & \multicolumn{2}{|c|}{ Centro } & \multicolumn{2}{|c|}{ Sur } & \multicolumn{2}{|c|}{ Golfo } & \multicolumn{2}{|c|}{ Peninsula } \\
\hline & 2000 & 2010 & 2000 & 2010 & 2000 & 2010 & 2000 & 2010 & 2000 & 2010 & 2000 & 2010 & 2000 & 2010 & 2000 & 2010 & 2000 & 2010 \\
\hline Ocupaciones calficadas $^{1}$ & 9.6 & 17.3 & 7.7 & 13.4 & 9.0 & 12.6 & 9.6 & 13.1 & 5.8 & 10.0 & 8.0 & 12.7 & 12.8 & 14.1 & 11.5 & 14.7 & 10.7 & 10.8 \\
\hline Trabajadores en la construcción ${ }^{2}$ & 22.9 & 22.1 & 28.2 & 27.3 & 23.0 & 22.0 & 29.4 & 32.0 & 38.4 & 34.0 & 31.7 & 30.8 & 30.2 & 31.2 & 22.2 & 23.7 & 26.1 & 29.3 \\
\hline Servicios personales ${ }^{3}$ & 22.8 & 22.8 & 13.3 & 18.2 & 19.3 & 23.9 & 13.8 & 18.4 & 11.9 & 17.2 & 14.2 & 19.7 & 14.7 & 21.2 & 17.9 & 24.1 & 16.9 & 22.1 \\
\hline Comercio y empleados & 92 & 9.9 & 7.8 & 8.7 & 10.4 & 10.4 & 10.1 & 9.6 & 8.8 & 8.7 & 10.0 & 11.3 & 8.9 & 10.6 & 11.1 & 11.5 & 7.9 & 8.4 \\
\hline Artesanos $\mathrm{y}$ trabajadores industriales ${ }^{4}$ & 23.1 & 16.7 & 34.6 & 24.5 & 26.7 & 18.5 & 26.7 & 18.5 & 26.4 & 22.7 & 25.2 & 17.2 & 21.7 & 14.3 & 23.3 & 16.6 & 22.8 & 16.9 \\
\hline Trabajo doméstico & 0.6 & 0.3 & 0.3 & 0.3 & 0.3 & 0.6 & 0.4 & 0.3 & 0.4 & 0.3 & 0.5 & 0.2 & 0.9 & 0.2 & 0.7 & 0.2 & 0.8 & 1.3 \\
\hline Auxiliares administrativos ${ }^{5}$ & 9.9 & 8.9 & 7.0 & 6.6 & 10.0 & 10.8 & 7.5 & 5.3 & 6.7 & 5.4 & 7.5 & 5.6 & 8.8 & 5.8 & 9.8 & 6.7 & 12.5 & 9.6 \\
\hline \multirow[t]{3}{*}{ Vendedores ambulantes } & 1.8 & 1.9 & 1.1 & 1.0 & 1.3 & 1.2 & 2.6 & 2.8 & 1.6 & 1.8 & 2.9 & 2.4 & 1.9 & 2.4 & 3.5 & 2.5 & 2.3 & 1.7 \\
\hline & 100.0 & 100.0 & 100.0 & 100.0 & 100.0 & 100.0 & 100.0 & 100.0 & 100.0 & 100.0 & 100.0 & 100.0 & 100.0 & 100.0 & 100.0 & 100.0 & 100.0 & 100.0 \\
\hline & 157,061 & 173,894 & 129,617 & 123,341 & 66,358 & 75,003 & 202,320 & 274,224 & 305,516 & 425,890 & 508,299 & 702,318 & 244,253 & 330,306 & 251,202 & 375,813 & 61,583 & 73,511 \\
\hline \multicolumn{19}{|c|}{ 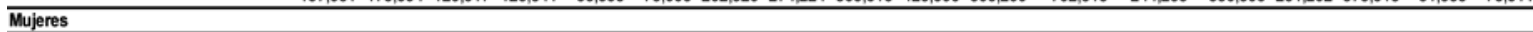 } \\
\hline Ocupaciones calficadas ${ }^{1}$ & 13.8 & 18.8 & 12.0 & 16.1 & 14.6 & 15.3 & 10.8 & 12.4 & 8.7 & 10.7 & 11.0 & 14.7 & 10.2 & 12.5 & 13.5 & 14.2 & 8.9 & 8.5 \\
\hline Trabajadores en la construcción ${ }^{2}$ & 0.8 & 1.6 & 1.6 & 0.6 & 0.8 & 0.6 & 0.6 & 0.6 & 0.9 & 0.6 & 0.6 & 0.5 & 0.3 & 0.4 & 0.3 & 0.5 & 0.1 & 0.5 \\
\hline Servicios personales ${ }^{3}$ & 14.6 & 14.3 & 3.1 & 12.8 & 4.4 & 14.9 & 6.6 & 15.2 & 4.5 & 9.8 & 4.1 & 11.2 & 4.4 & 12.1 & 5.3 & 16.2 & 3.5 & 12.6 \\
\hline Comercio y empleados & 19.7 & 23.5 & 15.5 & 23.7 & 19.4 & 24.8 & 23.1 & 24.8 & 19.5 & 24.3 & 16.9 & 22.8 & 15.8 & 25.0 & 20.4 & 25.1 & 15.4 & 20.5 \\
\hline Artesanos y trabajadores industriales ${ }^{4}$ & 20.7 & 17.4 & 34.6 & 18.4 & 25.9 & 15.1 & 25.9 & 16.8 & 31.2 & 24.3 & 27.5 & 18.4 & 32.8 & 25.7 & 15.0 & 10.8 & 30.9 & 28.3 \\
\hline Trabajo doméstico & 12.5 & 8.1 & 22.0 & 12.8 & 17.5 & 10.9 & 19.9 & 12.1 & 23.9 & 16.4 & 27.0 & 17.2 & 25.6 & 9.5 & 29.4 & 14.9 & 31.1 & 14.3 \\
\hline \multirow{2}{*}{ Vendedores ambulantes } & 100.0 & 100.0 & 100.0 & 100.0 & 100.0 & 100.0 & 100.0 & 100.0 & 100.0 & 100.0 & 100.0 & 100.0 & 100.0 & 100.0 & 100.0 & 100.0 & 100.0 & 100.0 \\
\hline & 70,203 & 91,091 & 68,064 & 59,477 & 27,681 & 32,634 & 133,361 & 190,989 & 155,977 & 252,011 & 264,976 & 412,030 & 193.073 & 246,309 & 154,515 & 223,892 & 36,569 & 43,325 \\
\hline \multicolumn{19}{|c|}{ - } \\
\hline Ocupaciones calficadas ${ }^{1}$ & 10.9 & 17.8 & 9.2 & 14.2 & 10.6 & 13.4 & 10.1 & 12.8 & 6.8 & 10.3 & 9.0 & 13.4 & 11.7 & 13.4 & 12.3 & 14.5 & 10.0 & 9.9 \\
\hline Trabajadores en la construcción ${ }^{2}$ & 16.1 & 15.1 & 19.0 & 18.6 & 16.5 & 15.5 & 18.0 & 19.1 & 25.7 & 21.6 & 21.0 & 19.6 & 17.0 & 18.0 & 13.8 & 15.0 & 16.4 & 18.6 \\
\hline Servicios personales ${ }^{3}$ & 20.3 & 19.9 & 9.8 & 16.5 & 14.9 & 21.2 & 10.9 & 17.1 & 9.4 & 14.4 & 10.8 & 16.6 & 10.1 & 17.4 & 13.1 & 21.1 & 11.9 & 18.6 \\
\hline Comercio y empleados & 12.4 & 14.6 & 10.5 & 13.6 & 13.0 & 14.7 & 15.3 & 15.9 & 12.4 & 14.5 & 12.4 & 15.6 & 12.0 & 16.8 & 14.7 & 16.5 & 10.7 & 12.9 \\
\hline Artesanos $\mathrm{y}$ trabajadores industriales ${ }^{4}$ & 22.3 & 16.9 & 34.6 & 22.5 & 26.4 & 17.5 & 26.4 & 17.8 & 28.0 & 23.3 & 26.0 & 17.7 & 26.6 & 19.2 & 20.2 & 14.4 & 25.8 & 21.2 \\
\hline Trabajo dom & 4.3 & 3.0 & 7.8 & 4.4 & 5.4 & 3.7 & 8.2 & 5.1 & 8.3 & 6.3 & 9.6 & 6.5 & 11.8 & 4.2 & 11.6 & 5.7 & 12.1 & 6.1 \\
\hline Auxiliares administrativos ${ }^{5}$ & 11.9 & 10.6 & 8.0 & 8.8 & 11.5 & 12.3 & 8.4 & 7.4 & 7.5 & 72 & 8.0 & 7.7 & 7.9 & 7.5 & 10.2 & 9.2 & 10.9 & 10.1 \\
\hline \multirow[t]{3}{*}{ Vendedores ambulantes } & 1.8 & 2.1 & 1.1 & 1.5 & 1.6 & 1.6 & 2.8 & 4.8 & 1.8 & 2.5 & 3.2 & 3.0 & 2.9 & 3.5 & 4.2 & 3.4 & 2.2 & 2.6 \\
\hline & 100.0 & 100.0 & 100.0 & 100.0 & 100.0 & 100.0 & 100.0 & 100.0 & 100.0 & 100.0 & 100.0 & 100.0 & 100.0 & 100.0 & 100.0 & 100.0 & 100.0 & 100.0 \\
\hline & 227,264 & 264,985 & 197,681 & 182.818 & 94,039 & 107,637 & 335,681 & 465.213 & 461,493 & 677,901 & 773,275 & $1,114,348$ & 437,326 & 576,615 & 405,717 & 599,705 & 98,152 & 116,836 \\
\hline
\end{tabular}

regiones y, para sorpresa nuestra,presentan una tendencia creciente para el año 2010.

\section{Comentarios finales}

La intención de este trabajo se ha centrado en: a) contribuir en el debate sobre los cambios en las actividades económicas que se están presentando en las áreas rurales y mostrar la heterogeneidad laboral al interior de las áreas rurales del país, por lo tanto, se tendría que hablar de distintos grados de ruralidad, desde el punto de vista de la composición del empleo que se presenta en cada una de las regiones que se revisaron; b) en mostrar la heterogeneidad en las tendencias en la composi- ción de las ocupaciones según la región de residencia y género; y c) señalar que la oferta de trabajos agrícolas y no agrícolas en las zonas rurales es limitada. Y que la tendencia de crecimiento en las ocupaciones no agropecuarias hacia las que está transitando un amplio conjunto de la población, son de baja productividad y ofrecen limitadas o nulas condiciones laborales.

La expansión de las empresas agrícolas fue un fenómeno que consolidó a la modernización de la agricultura para la producción nacional como extranjera. En tanto que la oferta de empleos asalariados fue limitada, debido a que estas formas de producción, en general, son ahorradoras de mano de obra.

15 Fuente: cálculos propios a partir de la Muestra del censo de población y vivienda del 2000 y 2010.

1. Incluye a funcionarios, directores y jefes de los sectores público, privado y social; pofesionistas y técnicos.

2. Incluye: Albañiles mamposteros y afines; trabajadores en la extracción y edificaciones de construcciones y trabajadores de apoyo en la construcción.

3. Incluye: Trabajadores en la preparación y servicio de alimentos y bebidas; servicios personales y vigilancia; conductores de transporte y maquinaria móvil; de camiones de carga de autobuses, camiones, taxis de pasajeros.

4. Incluye: Artesanos y trabajadores en el tratamiento de productos de metal, madera, papel, productos textiles, alimentos, bebidas, productos de tabaco y productos de hule, plástico, sustancias químicas y cerámica.

5. Incluye: Trabajadores auxiliares en actividades administrativas y trabajadores de limpieza, de paquetería y repartidores de mercancías. 
Por otra parte, se han presentado elementos que ilustran como los cambios económicos han dejado en grandes desventajas a los pequeños productores, que han tenido que insertarse en empleos de baja productividad que en la actualidad se han vuelto centrales para el ingreso de los hogares rurales.

Por lo que se puede decir, que sus condiciones no han mejorado a pesar de que han cambiado de actividad económica. Y que esta situación se puede atribuir a una escaza oportunidad de empleos en las áreas rurales y a las limitadas credenciales que tiene la población agropecuaria.

De esta forma se ha podido establecer que existe un conjunto de ocupaciones agropecuarias, con mayor importancia dentro de cada una de las regiones revisadas, que aluden a la especialización de algunos cultivos vinculados con la exportación y la localización de la producción de autoconsumo. Y por otro lado, se han presentado las regiones en las que las ocupaciones no agropecuarias tienen una mayor importancia. Esto permite establecer diferencias en los mercados de trabajo, tanto agropecuarios como no agropecuarios. Igualmente, los habitantes de algunas regiones, como la Noroeste y Norte, cuentan con mayores ventajas en la incorporación en trabajos asalariados a diferencia de lo que ocurre en la región Sur.

Se observa la importancia que han ido cobrando las ocupaciones como el comercio y los servicios entre las distintas regiones, que se refiere principalmente a ocupaciones de refugio que se han manifestado como una respuesta de la población frente a la baja rentabilidad de la agricultura. El que se hayan incorporado en estas ocupaciones no significa, en la mayoría de los casos, que se encuentren en mejores condiciones económicas.

Las ocupaciones que se han expandido en los contextos rurales aluden al autoempleo, ya que gran parte de ellas no son calificadas, de apoyo y que ofrecen las condiciones laborales precarias. En contraparte, las ocupaciones calificadas como los profesionistas y los técnicos no se han incrementado sustantiva- mente, ya que los incrementos porcentuales han sido moderados. En parte se debe a las limitadas oportunidades que se ofrecen en los contextos rurales y al aislamiento de muchas de las localidades rurales para vincularse con mercados de trabajo urbanos cercanos, solamente escapan a esta situación en lagunas regiones como el Centro y Centro-Norte.

Se ha logrado confirmar el descenso de las ocupaciones agropecuarias a nivel nacional, sobre todo la que se encontraba en el cultivo de maíz y fríjol. Sin embargo, siguen siendo una fuente de empleo muy importante para la población rural, sobre todo en algunas regiones como el Sur.

Se ha ratificado que la población ocupada femenina se encuentra desempeñando actividades no agropecuarias principalmente y al parecer esta tendencia no se revertirá, debido a que se ha documentado que históricamente las ocupaciones en las que se han insertado las mujeres son las no agropecuarias (Arias, 2009). Esta tendencia se ha manifestado de manera clara a nivel nacional, a pesar de que algunos especialistas han mencionado la importancia de la mano de obra femenina calificada en ciertos partes de la producción en la agroindustria.

De esta forma se puede comprobar la persistencia de la población ocupada masculina en actividades agropecuarias. A pesar de que mantienen una tendencia descendente como se manifiesta en el cultivo de maíz y frijol. Pero llama la atención el incremento de la mano de obra masculina en el cultivo de hortalizas, frutas y flores, en el que las mujeres habían tenido una participación importante en el inicio de este siglo.

Estos procesos aluden al incremento de las ocupaciones denominadas de refugio como una consecuencia de los cambios económicos y estructurales que se han experimentado en el campo mexicano desde hace algunas décadas. A lo largo de este proceso se ha logrado documentar que existe una contracción en el mercado laboral de las áreas rurales tanto en ocupaciones agropecuarias como no agropecuarias, tanto asalariado como no asalariado. 


\section{Referencias}

Appendini, K. (1992). "La 'modernización' en el campo y el futuro del campesinado: iniciamos el debate de 'los noventa'”. En Estudios Sociológicos, X (29): 251-262.

Appendini, K. (2008). "II. La transformación de la vida rural en tres ejidos del centro de México". En KirstenAppendini \& Gabriela Torres-Mazuera (editoras). ¿Ruralidad sin agricultura?, México, El Colegio de México: 27-58.

Appendini, K. \& Torres-Mazuera, G. (2008). "I. Perspectivas multidisciplinarias de una realidad fragmentada". En Kirsten Appendini \& Gabriela Torres-Mazuera (editoras). ¿Ruralidad sin agricultura?, México, El Colegio de México: 13-26

Arias, P. (1995), "La migración femenina en dos modelos de desarrollo: 1940-1970 y 1980-1992”. En Soledad González \& VaniaSalles (coordinadoras). Relaciones de género y transformaciones agrarias. Estudios sobre el campo mexicano, El Colegio de México, PIEM.

Arias, P. (2009). Del arraigo a la diáspora. Dilemas de la familia rural, México, Miguel Ángel Porrúa.

Arizpe, L. \& Aranda, J. (1986). "Women Workers in the Strawberry in Agribusiness Mexico". En: Helen Safa, et al. Women's Work, Development and the Division of Labor by Gender, Massachussets, Bergin and Garvey: 174-195.

Berdegué, J. (2002). "Las reformas de los sistemas de extensión en América Latina a partir de la década de los 80". Santiago de Chile disponible en: RIMISP: 22 http://rimisp.cl/getdoc. php?docid=818 (20/12/2005)

Consejo Nacional de Población (CONAPO), (2004). Informe de ejecución del Programa de acción de la Conferencia Internacional sobre la población y el desarrollo, 1994-2003, México.

De Janvry, A. \& Saudelet, E. (2002). "Estrategias de ingresos de los hogares rurales de México: el papel de las actividades desarrolladas fuera del predio agrícola". En: CEPAL Empleo e ingresos rurales no agrícolas en América Latina, Seminarios y conferencias, 35:107-128.

Dirven, M. (2002). La práctica de herencia de tierras agrícolas: ¿una razón más para el éxodo de la juventud?. En: serie Desarrollo productivo, № 135, CEPAL, Santiago de Chile.

Dirven, M. (2004). "El empleo rural no agrícola y la diversidad rural en América Latina". En: Revista de la CEPAL, № 83, Santiago de Chile.

Esquivel, G. (2009). El mercado laboral en México: caracterización y agenda de investigación. CEPAL, LC/MEX/L.894.

García, B. \& Oliveira, O. (1998). "La participación femenina en los mercados de trabajo". En: Revista Trabajo, Centro de Análisis del Trabajo A.C., 1 (1), enero junio.

Garay, S. (2008). Trabajo Rural Femenino: Tendencias recientes, Tesis doctoral, CEDUA-El Colegio de México.

Grammont, H. C. \& Lara, S. (2005). Encuesta a hogares de jornaleros migrantes en regiones hortícolas de México: Sinaloa, Baja California Sur y Jalisco, IIS-UNAM, México, Cuadernos de investigación 30.

Grammont, H. (2009). "La desagrarización del campo mexicano", en Convergencia. En: Revista de Ciencias Sociales, 50, Universidad del Estado de México:13-55.
Grammont, H. (2010). “¿Nueva ruralidad o nueva sociología rural?”. Ponencia presentada en el VIII Congreso de la Asociación Latinoamericana de Sociología Rural, Porto de Galinhas, Pernambuco.

Grammont, H. C. (2004). "La nueva ruralidad en América Latina". En: Revista Mexicana de Sociología, 66, número especial: 279-300.

Köbrich, C. \& Dirven, M. (2007). Características del trabajo rural no agrícola en América Latina con énfasis en los servicios. En: Serie Desarrollo productivo CEPAL, Santiago de Chile.

Lara, S. (2011). "Precarización del trabajo asalariado en la agricultura". En: Edith Pacheco (coordinadora). Trabajos atípicos y precarización del empleo, en prensa, México: 367-399.

Larralde, A. H. (2008). "Mercados de trabajo en localidades rurales del centro de México: algunas características sociales y espaciales". En: Kirsten Appendini \& Gabriela Torres-Mazuera (editoras), ¿Ruralidad sin agricultura, El Colegio de México, México: 79-102.

Lastarria-Cornhiel, S. (2008). Feminización de la agricultura en América Latina y África. Tendencias y fuerzas impulsoras, Rimisp-Centro Latinoamericano para el Desarrollo Rural, Santiago.

Llambí, L. \& Pérez, E. (2006). "Nuevas ruralidades y viejos campesinos. Agenda para una nueva sociología rural latinoamericana". Ponencia presentada en el VII Congreso de la Asociación Latino Americana de Sociología Rural (ALASRU).

Mummert, G. (1992). "Changing Family Structure and Organization in a Setting of Male Emigration, Female Salaried Work and the Commercialization of Agriculture: A Case Study from Michoacán, Mexico". Conferencia presentada en el Seminario de Inbestigación sobre relaciones México-Estados Unidos, Centro de Estudios sobre Estados Unidos y México, Universidad de California en San Diego, 11 marzo.

Pacheco, E. (2006). "El trabajo agropecuario en México: 19912003". En: Enrique de la Garza \& Carlos Salas (coordinadores). La situación del trabajo en México 2006, Plaza y Valdez, México.

Pacheco Ladrón de Guevara, L. (2000). Juventudes rurales en México. Encuesta Nacional de la Juventud, Instituto Mexicano de la Juventud, México. Documento de trabajo.

Pacheco Ladrón de Guevara, L. (2006), "De la protección de la comunidad rural a la levedad de la ciudadanía en los jóvenes rurales de México". Ponencia presentada en el VII Congreso de la Asociación Latinoamericana de Sociología Rural, Quito.

Pedrero, M. \& Embriz, A. (1992). "Los mercados de trabajo en las zonas rurales. Notas sobre la Encuesta Nacional de Empleo de 1988". En: Estudios Sociológicos, X (29): 363-388.

Rendón, T. (2003). Trabajo de hombres y trabajo de mujeres en el México del siglo XX, CRIM-PUEG-UNAM, México.

Rubio, B. (2001). Explotados y excluidos: los campesinos latinoamericanos en la fase agroexportadora neoliberal, México, Plaza y Valdez.

Rubio, B. (2004), "El sector agropecuario mexicano en los años noventa: subordinacióndesestructurante y nueva fase productiva". En: Blanca Rubio (coordinadora). El sector agropecuario mexicano frente al nuevo milenio, Plaza y Valdez, UNAM: 17-43.

Saavedra, F. \& Rello, F. (2010). Dimensiones estructurales de la agricultura y el desarrollo rural en México. México, Banco Munidal, Flacso-México.

Szasz, I. (1990), "Dimensiones del mercado de trabajo, migraciones temporales y reproducción doméstica. Un caso en la zona rural del Estado de México". En: Revista Mexicana de Sociología, 52 (1): 151-167. 
Szasz, I. (1999). "La perspectiva de género en el estudio de la migración femenina en México". En: Brígida García (coordinadora). Mujer, género y población en México, El Colegio de México, México: 167-210.

Trejo, J. (2003). "Características del empleo rural". En: CEPAL Medición y caracterización del empleo en las encuestas de hogares, Buenos Aires: 157-179.

Yúnez, A. \& Meléndez-Martínez, A. (2007). "Efectos de los activos familiares en la selección de actividades y en el ingreso de los hogares rurales de México". En: Investigación Económica, LXVI (260), abril-junio: 49-80.

Yúnez-Naude, A. \& Taylor, J.E. (2001). "The determinants of nonfarm activities and incomes of rural household in Mexico, with emphasis on education". En: World Development, 29 (3), edición especial, Amsterdam. 